\title{
POLÍTICAS PARA A EDUCAÇÃO INCLUSIVA, DIVERSIDADE CULTURAL E A FORMAÇÃO DE PROFESSORES: PRIMEIRAS APROXIMAÇÕES
}

\author{
Jani Alves da Silva Moreira - Universidade Estadual de Maringá/Brasil \\ Nicole de Oliveira Lima - Universidade Estadual de Maringá/Brasil
}

RESUMO: Este texto tem como objetivo compreender a política para a Educação Inclusiva no Brasil, no contexto da propalada diversidade cultural. Trata-se de uma pesquisa exploratória, de análise bibliográfica que abordou as primeiras aproximações sobre o tema. Considera-se que a perspectiva da sducação inclusiva diante da divdersidade cultural deve ser entendida sob o aspecto de incluir a todos e todas no sistema educacional, sendo assim, engloba todas as pessoas que, historicamente são excluídas do acesso e do direito a aprendizagem e ao desenvolvimento no espaço educacional, sejam elas, crianças e adolescentes pobres, negros, indígenas, outras etnias, imigrantes, em conflito com a lei, com necessidades educacionais especiais, com deficiências, jovens e adultos em atraso escolar, diferentes identidades e orientação sexual, entre outros. O tema é relevante, pois se refere a um dos desafios a ser alcançado na Agenda E2030, no qual carece de uma compreensão crítica para identificar os desafios, avanços e retrocessos no campo da Educação Inclusiva.

Palavras-chave: Educação Inclusiva. Políticas Educacionais. Diversidade. Formação de Professores

ABSTRACT: This text aims to understand the policy for Inclusive Education in Brazil, in the context of the propagated cultural diversity. It is an exploratory research, of bibliographic analysis that approached the first approaches on the theme. It is considered that the perspective of inclusive education in the face of cultural diversity must be understood from the perspective of including everyone in the educational system, thus encompassing all people who, historically, have been excluded from access and the right to learning and to development in the educational space, whether they are poor children and adolescents, blacks, indigenous people, other ethnicities, immigrants, in conflict with the law, with special educational needs, with disabilities, young people and adults in backward school, different identities and sexual orientation, among others. The theme is relevant, as it refers to one of the challenges to be achieved in Agenda E2030, in which it lacks a critical understanding to identify the challenges, advances and setbacks in the field of Inclusive Education.

Keywords: Inclusive Education. Educational Policies. Diversity. Teacher training.

\section{INTRODUÇÃO}

A presente texto aborda o tema políticas para a Educação Inclusiva no Brasil a partir da compreensão da categoria Diversidade Cultural envolta nas definições políticas para a inclusão social na escola e na sociedade. Trata-se dos resultados de uma pesquisa que proporcionou uma primeira aproximação ao tema investigado, no qual 
Políticas para a educação inclusiva, diversidade cultural e a formação de professores: primeiras aproximações

compreendeu-se o processo histórico da Educação Inclusiva e da Diversidade Cultural na educação. Considerou-se a compreensão dos aspectos legais e influenciadores das políticas e da nova face de uma educação inclusiva para todos.

Ao analisar a perspectiva da educação inclusiva foi necessário, compreendermos o processo histórico que implica o assunto em questão, uma vez que a demanda de um atendimento diferenciado para pessoas com necessidades especiais, de acordo com Ministério da Educação (2008) teve início no Brasil Império, no século XIX, com a fundação de duas instituições, ambas no Rio de Janeiro: o Imperial Instituto dos Meninos Cegos, atual Instituto Benjamin Constant (IBC), e o Instituto dos Surdos Mudos, hoje designado Instituto Nacional da Educação dos Surdos (INES). A partir do Século XX foi que começaram a existir avanços acerca das discussões sobre o assunto. Novas instituições para atender pessoas com necessidades especiais foram criadas e novas leis, planos e diretrizes principiaram a amparar a garantia da educação inclusiva no Brasil, nomeadamente, com o intuito de incluir pessoas com necessidades específicas no sistema regular de ensino.

Em 1961, o atendimento educacional às pessoas com deficiência passa a ser fundamentado pelas disposições da Lei de Diretrizes e Bases da Educação Nacional - LDBEN, Lei n ${ }^{\circ} 4.024 / 61$, que aponta o direito dos "excepcionais" à educação, preferencialmente dentro do sistema geral de ensino (BRASIL, 2008, p. 6).

No entanto foi com a LDB n ${ }^{\circ} 5.692 / 71$ que nos deparamos com um cenário não apropriado para atender as progressões idealizadas e a educação igualitária para todos, no entanto, esse alcance ainda parece estar longe de ser impetrado:

A Lei no $5.692 / 71$, que altera a LDBEN de 1961, ao definir "tratamento especial"
para os estudantes com "deficiências físicas, mentais, os que se encontram em
atraso considerável quanto à idade regular de matrícula e os superdotados", não
promove a organização de um sistema de ensino capaz de atender aos estudantes
com deficiência, transtornos globais do desenvolvimento e altas
habilidades/superdotação e acaba reforçando o encaminhamento dos estudantes
para as classes e escolas especiais (BRASIL, 2008, p. 7).

A partir da década de 1990 em meio às reformas neoliberais no contexto de reforma do aparelho do Estado, o contexto do atendimento às pessoas com algum tipo de deficiência ou com necessidade de inclusão no sistema educacional regular, passou por uma nova intitulação. Com a globalização econômica e as novas alianças junto aos 
organismos internacionais, em 1994 a Declaração de Salamanca preconizou uma estruturação da política, com o proclamado conceito de uma escola inclusiva a fim garantir políticas de educação igualitária, independente de quaisquer diferenças sociais, econômicas e de aprendizado, que poderiam ocorrer. Parece-nos que a partir daí surgem preocupações que passam a orientar a prática de professores, pais e alunos.

A educação de alunos com necessidades educativas especiais incorpora os princípios já comprovados de uma pedagogia saudável da qual todas as crianças podem beneficiar, assumindo que as diferenças humanas são normais e que a aprendizagem deve ser adaptada às necessidades da criança, em vez de ser esta a ter de se adaptar a concepções pré-determinadas, relativamente ao ritmo e à natureza do processo educativo (UNESCO, 1994 p.6)

O objetivo principal está então, naquilo que fora proporcionado para que a educação inclusiva fosse efetivada, conhecer as exigências almejadas para que a mudança ocorresse na prática. $\mathrm{O}$ foco essencial vai de encontro com as relações dos profissionais. Quando se trata de inclusão é preciso considerar todo o conjunto que forma a escola, não só aqueles que carecem da inclusão, portanto, que atuam diretamente.

O número de alunos com necessidades especiais cresce continuamente nas escolas, paralelo a isso as instituições com especialização em educação especial também, aproximarmo-nos das propostas existentes para compreender este aspecto, contribuem para a formação integral da comunidade escolar. Pensar em educação inclusiva é pensar também em uma reorganização institucional, uma vez que essas são percussoras de um diálogo que propõe a ação em conjunto - professor- aluno-gestão- família.

Diante das estimativas de melhorias na educação, a inclusão de alunos, que apresentam deficiência, no sistema geral de ensino, garante a totalidade de uma aprendizagem de qualidade e igualitária. De acordo com algumas pesquisas, entre 2005 e 2015, o salto foi o equivalente a 6,5 vezes, de acordo com o Censo Escolar, do Inep (INEP, 2014). O total subiu de 114.834 para 750.983 estudantes especiais convivendo com os demais alunos. Como se vê, os dados demonstram que o número de pessoas com deficiências e necessidades específicas nas salas de aula, cresce significativamente a cada ano e, mesmo com essa realidade, são poucos os profissionais habilitados para exercerem a prática nessa modalidade de ensino. A falta de conhecimento gera, muitas vezes, uma visão retrógrada àquilo que gostaríamos de alcançar e retarda o alcance do objetivo ideal final. 
Políticas para a educação inclusiva, diversidade cultural e a formação de professores: primeiras aproximações

\section{PRESSUPOSTOS HISTÓRICOS, POLÍTICOS DA EDUCAÇÃO INCLUSIVA NO CONTEXTO DO NEOLIBERALISMO E DA GLOBALIZAÇÃO}

Ao tratar de forma sucinta sobre os pressupostos históricos e política da educação inclusiva no país, se faz necessário resgatar questões relacionadas a compreensão do papel dos organismos internacionais na composição e determinação da agenda política na América Latina e no Caribe, especificamente na perspectiva da educação inclusiva. Nas últimas décadas, a definição da agenda política para a educação tem sido com base em orientações de agências internacionais, sobretudo Organização das Nações Unidas para a Educação, Ciência e a Cultura (UNESCO) tem coordenado o processo de acordo e cooperação técnica no alcance das metas acordadas na Agenda E2030 (MOREIRA, 2019).

As políticas educacionais têm sido determinadas diante das conduções pautadas no neoliberalismo de ações afirmativas, voltadas para grupos socialmente excluídos e com o intuito de tratar apenas das suas especificidades. No caso da diversidade cultural, esta passa a ser o foco das discussões em torno do combate ao racismo e à discriminação, com vistas à construção da paz social. A diversidade cultural é definida pela UNESCO (2005) como uma multiplicidade de meios pelos quais se expressa a cultura dos grupos sociais e sociedades, sendo um tema recente, porém de grande presença nas políticas públicas para educação. Nesse sentido, a ênfase na diversidade cultural-étnica, racial, no combate a preconceitos ligados às questões de gênero, religião, deficiências, padrões culturais e outros aspectos estão cada vez mais recorrentes nos debates. E sob essa concepção é que se pauta o conceito de Educação Inclusiva, que deve incluir a todos que que se inserem em questões relacionadas ao gênero, sobretudo para evitar o aumento da pobreza, violência e preconceito.

As políticas educacionais configuradas a partir da década de 1990 tiveram em sua essência as orientações decorrentes dos eventos internacionais realizados em Jomtien (1990) e Nova Delhi (1993), que traçaram metas para a reforma educacional que foi a condição para o equilíbrio da desigualdade via equidade social, por meio da inclusão de todos na sociedade.

Outra questão que contribuiu para essa mudança foi a reforma do aparelho do Estado que teve sua base ideológica política e econômica no neoliberalismo. A partir da crise econômica dos anos de 1970, nos Estados Unidos e Inglaterra, transformando-se em 
uma crise política em "todas as instituições do Estado e os métodos organizacionais correspondentes" (MÉSZÁROS, 2002, p. 106).

Um processo de reformas foi iniciado em diversos países desenvolvidos, colocando em risca o estado do bem estar social e, posteriormente, nos países em desenvolvimento, no qual as ideias para o regulamento do mercado foram sendo disseminadas na sociedade capitalista e adotaram políticas de liberalização e reformas voltadas para a desregulamentação da economia e do estado mínimo. Salienta-se que de acordo com Sandroni (1994, p. 240), “o neoliberalismo é uma doutrina políticoeconômica que representa uma tentativa de adaptar os princípios do liberalismo econômico às condições do capitalismo moderno".

As políticas neoliberais no Brasil, que tiveram início na década de 1990, foram difundidas pelo governo de Fernando Collor de Melo (1990-1992), o qual permaneceu como horizonte político no governo de Fernando Henrique Cardoso (1995-2002). Assim, as reformas educacionais que partiram desses dois governos passaram a se basear na visão gerencial, a qual prega um mercado competitivo e regulador, o que caracteriza a Reforma do Estado Brasileiro (OLIVEIRA; FONSECA, 2005).

As propostas difundidas pelo ideário neoliberal resultaram em mudanças estruturais nos campos econômico e social. No campo econômico, ocorreram privatizações em alguns setores, como nas telecomunicações, deixando o Estado de ser o executor direto desses serviços. É no campo social, que se assenta a perspectiva da Educação Inclusiva e das políticas para atender as diversas diferenças ou as diversas necessidades específicas, provenientes de aspectos culturais, econômicos, sociais e biopsicológicos. A questão das "diferenças" sociais passou a ser tratada naturalmente, considerando-se desigualdades e injustiças como aspectos relacionados à falta de formação humana adequada e necessária para o desenvolvimento de uma sociedade pautada na liberdade, igualdade e direito de todos. Nesse sentido, a educação e o "estar na escola" seria condição para o fim da discriminação e a falta de respeito às diversidades presentes na sociedade.

Esse contexto no Brasil representou um período de intensa formulação de documentos orientadores e planejadores da política, como o Plano Nacional de Educação para Todos (1993) e os Parâmetros Curriculares Nacionais (1997), sendo instituída como a década da educação, com a democratização e universalização da Educação Básica, com a inclusão de "todos" a partir da "tolerância" e do respeito à diversidade no espaço 
Políticas para a educação inclusiva, diversidade cultural e a formação de professores: primeiras aproximações

escolar. A referida autora ainda destaca que a legislação aprovada nos anos de 1990 trouxe outra forma de gestão e financiamento da educação, por meio de uma gestão "compartilhada" e "parcerias" entre Estado e a sociedade em diversos setores.

Nesse contexto, a proposta da universalização e de educação para todos inseridos em uma sociedade cuja base é a homogeneização da classe dominante, seus valores e ideais podem não se concretizar efetivamente, tornando-se apenas discurso. Sendo assim, Canen (2000) também afirma que devemos desconfiar do discurso sobre o respeito e a tolerância as diferenças "isto porque o que pode estar em jogo é a "adaptação" encaixe dos "diferentes" ao modelo hegemônico, não importando a violência exercida sobre as diversas culturas, raças e etnias". Com base nessas considerações, é importante ressaltar que o conceito de tolerância, refere-se ao ato ou efeito de tolerar, de ser paciente e compreensivo.

De acordo com Moreira, Pinelli, Matsuo (2011) a influência da globalização na sociedade contemporânea pode ser evidenciada em diversos setores e, de forma mais acentuada, na escola. O campo educacional, levando em consideração o surgimento de uma sociedade globalizada, prioriza uma política educacional que reconheça as diferenças étnicas, sociais e culturais, sendo essa uma maneira encontrada pela UNESCO para acabar com o racismo, a intolerância e o preconceito.

Para compreender o contexto da produção política na década de 1990 que foi marcada por muitas alterações sociais, retomamos alguns preceitos que compõem a base para a política da diversidade cultural e da política educacional da educação inclusiva. Com o esgotamento do modelo taylorista/fordista, da política keynesiana e do Estado de bem-estar social (EBES), a economia mundial passou por uma fase crítica. Assim, o capitalismo, para superar essa crise, utilizou-se de mecanismos como a globalização, financeirização e reestruturação produtiva. Assim sendo, desde a década de 1980, a economia mundial sofreu transformações, devido ao processo de globalização que tem suas origens no agrupamento de três forças: 1)a terceira revolução tecnológica (tecnologias ligadas a busca, processamento, difusão e transmissão de informações; inteligência artificial; engenharia genética); 2) a formação da área de livre comércio e blocos econômicos interligados [...]; 3) a crescente interligação patrimonial e a interdependência dos mercados industriais e financeiros, em escala planetária, ou seja, 
não apenas entre as principais economias capitalistas, mas com participação também dos países socialistas (FONSECA, 1997, p. 2).

A globalização, além de dispor dos desenvolvimentos de estruturas globais no poder e reconfigurar o poder do Estado-nação, também resignificou conceitos de democracia, cidadania e dos direitos e deveres dos atores sociais. Importa ressaltar que a cidadania é um modo de organizar e regular a sociedade e não apenas um conjunto de direitos sociais, sendo também associada à nacionalidade, ao espaço territorial da nação, organizando-se em fatores culturais (MOREIRA; PINELLI; MATSUO, 2011). Quando o Estado não oferece garantias de segurança e proteção, os cidadãos passam a agir livremente, sendo responsáveis por si mesmos, assim a "cidadania está sendo reinventada com maior ênfase na responsabilidade e maior incerteza em relação aos direitos" (REILLY, 1999, p. 411). Nesse contexto, a escola está sendo vista como um espaço de transformação da cidadania, devendo o sujeito agir por si mesmo e adequar-se à sociedade globalizada.

No período de recessão econômica e o aumento de pressões competitivas internacionais, na década de 1990, as empresas passaram a buscar maior espaço de acumulação, reestruturação e produção, inserindo novas tecnologias e criando um novo padrão de acumulação flexível. Assim, a defesa da diversidade teve destaque, pois com o avanço da globalização, juntamente com a flexibilização produtiva, acarretou na demanda de produzir bens diversificados e aumentar as opções de escolha do consumidor.

Carvalho (2010) atenta para o fato de que a política de valorização da diversidade cultural, no campo da educação, decorrente do processo de globalização, não ocorre de forma neutra e consensual. Afirma a autora, [...] ao contrário, ela se desenvolve em um terreno marcado pelas tensões e contradições que traduzem as lutas das forças sociais, políticas e culturais em jogo e que são caracterizadas pela oposição entre o universal e o particular, o local e o global, a objetividade e o relativismo, a igualdade e a diferença/diversidade (CARVALHO, 2010, p.45). A globalização uniformizou, padronizou a forma de consumo, todavia, as diferenças de classe se acirraram.

Documentos da Unesco foram considerados basilares na produção dos pilares da política da diversidade e tolerância. Torres (2008) destaca a presença de um viés moralista e solidário, muito presente no "Relatório para a Unesco da Comissão Internacional Sobre a Educação Para o Século XXI" com uma forte característica do sistema do capital, no 
Políticas para a educação inclusiva, diversidade cultural e a formação de professores: primeiras aproximações

qual as consequências são tratadas como causas. Nos Relatórios Cuéllar e Delors podemos apreender outra característica do sistema do capital que

[...] é a total incapacidade de tratar as causas como causas, não importando a gravidade de suas implicações a longo prazo". Em decorrência disso, nas necessárias ações remediadoras, são propostas [...] soluções para todos os problemas e contradições gerados, em sua estrutura por meio de ajustes feitos estritamente nos efeitos e nas consequências (MÉSZÁROS, 2002, p. 175).

Moreira, Pinelli e Matsuo (2011) enfatizam que convívio pacífico com as diferenças dependeria unicamente da "boa vontade" do indivíduo que, ao tolerar e respeitar as diferenças apaziguaria todos os conflitos sociais. No entanto, Torres (2008) destaca um ponto importante, que não é apontado no documento da UNESCO, sobre o papel da escola frente aos problemas sociais: A escola pode contribuir para diminuí-los, embora a melhoria das condições da consciência só se manifeste quando melhoram as condições materiais. Por isso, devemos nos preocupar com a forma com que são repartidos socialmente bens e serviços, lutando pela redistribuição e pela igualdade (TORRES, 2008, p. 30). Diante disso, o discurso em torno da diversidade cultural não pode ficar limitado à "diferença cultural”, mas deve ser analisado também na perspectiva da "desigualdade social", pois a base dos problemas sociais está na economia e deve ser visto também por este ângulo.

\section{EDUCAÇÃO INCLUSIVA, DIVERSIDADE E A FORMAÇÃO DE PROFESSORES}

Ao examinar os conceitos produzidos para as políticas na perspectiva da Educação Inclusiva e sua relação com a diversidade elencarmos algumas questões a se pensar no campo da formação de professores. De acordo com as mudanças ocorridas na sociedade, os avanços tecnológicos, a nova ordem do capital, a alta competitividade, as desigualdades e a exclusão social, são consequências que provocando, assim, [...] comportamentos sociais relacionados à erupção de novas formas de intolerância, violência, racismo, xenofobia, manifestação do nacionalismo, marginalização, discriminação contra as minorias étnicas, religiosas e linguísticas e ainda ao terrorismo" (CARVALHO, 2010, p. 41).

Mediante esses comportamentos alterações ocorrem nas políticas e práticas do âmbito educacional. Neste sentido a escola ficou “[...] desafiada a transmitir novos

Educação, Psicologia e Interfaces, Volume 3, Dossiê Inclusão e Diversidade, p. 122-134, 2019. ISSN: 2594-5343. DOI: https://doi.org/10.37444/issn-2594-5343.v3i4.232 
conhecimentos e formar novas competências, com o objetivo de preparar os seres humanos para as novas condições de vida, em consonância com a nova dinâmica do capitalismo" (CARVALHO, 2010, p. 42). A educação passa a caminhar conforme as novas leis do mercado, tendo como objetivo formar os indivíduos flexíveis, estimulandoos a adquirir as capacidades culturais e técnicas, para que possam acompanhar as transformações, conseguindo adaptar-se facilmente "às pressões imediatas e às incertezas inerentes à luta pela sobrevivência" (CARVALHO, 2010, p. 42). A educação também passa a ser vista como meio para a formação da chamada "cidadania ativa", no qual o indivíduo é responsável por si mesmo e pelo grupo. Torna-se responsável pelo desenvolvimento humano sustentável e pela formação da cidadania global, fortalecendo o indivíduo como cidadão, responsável pela construção de democracias multiétnicas e a paz mundial (CARVALHO, 2010). E no alcance dessas demandas está o professor, como o profissional ser responsável para alcançar esses bons resultados.

Um dos documentos internacionais que enfatiza essa nova forma de educação é o Relatório "Educação, um tesouro a descobrir", realizado pela Comissão Internacional sobre Educação para o século XXI, tendo como coordenador Jacques Delors. No relatório, a educação é orientada a seguir os caminhos do mundo globalizado. Com isto a educação passa a ser o "passaporte" para a "empregabilidade, a participação democrática, o desenvolvimento sustentável, a tolerância, a paz, a coesão social e a superação de todas as formas de exclusão". Em termos práticos, Delors aponta quatro pilares da educação: aprender a conhecer; aprender a fazer; aprender a viver juntos; aprender a ser (CARVALHO, 2010, p. 43). Assim, o "aprender a conhecer" significa "aprender a aprender para beneficiar-se das oportunidades oferecidas pela educação ao longo de toda a vida". O segundo pilar, "aprender a fazer", refere-se a capacidade do indivíduo de lidar com várias situações em contextos distintos (RIZO, 2010).

O "aprender a viver juntos" busca [...] desenvolver a compreensão do outro e a percepção das interdependências - realizar projetos comuns e preparar-se para gerir conflitos -no respeito pelos valores do pluralismo, da compreensão mútua e da paz" (DELORS, 2001, p. 102). E por último, o “aprender a ser” implica na busca de um novo indivíduo que tenha uma boa memória, raciocínio, sentido estético, capacidades físicas, aptidão para comunicar-se (MOREIRA, PINELLI, MATSUO, 2011).

Os princípios que orientam as reformas educativas no campo da Educação Inclusiva pautam-se nos seguintes aspectos: a) combate a todas as formas de preconceito 
Políticas para a educação inclusiva, diversidade cultural e a formação de professores: primeiras aproximações

e discriminação; b) compreensão e respeito ao Estado de Direito; c) fortalecimento de uma forma contemporânea de lidar com o público e o privado, especialmente quanto aos valores, atitudes e conceitos responsáveis, e envolvimento de pessoas em ONGs, em questões ambientais, dentre outras; d) valorização da participação, da solidariedade, do respeito e do senso de responsabilidade pelo outro e pelo público; e) formação de hábitos democráticos e responsáveis pela vida civil; f)garantia de igualdade de oportunidade e diversidade de tratamento; g)constituição de identidades capazes de suportar a inquietação, conviver com o incerto, o imprevisível e o diferente; h)reconhecimento e valorização da diversidade cultural, ou seja, das formas de se perceber e expressar a realidade própria dos gêneros, etnias, regiões, grupos sociais e países; i) responsabilidade por construir a cidadania num mundo que se globaliza (CARVALHO, 2010, p. 44).

Diante desse cenário, ponderam Moreira; Pinelli; Matsuo (2011) busca-se a construção de um pensamento social voltado para ações humanas que beneficiem a si próprio e a todos (RIZO, 2010). As diretrizes estabelecidas pela UNESCO, mediante Carvalho (2010) têm a pretensão de formar sujeitos capazes de: Compreender o mundo em sua pluralidade, incluindo o outro e suas características particulares, pelo princípio da tolerância, bem como interpretar sua própria cultura nesse universo plural de uma Terra globalizada. Vivenciar sua identidade cultural sem fazer dela motivo de fundamentalismos. Para isso, há a necessidade de reflexão sobre seus bens culturais e compartilhamento deles com o resto da humanidade, além da promoção do pensamento auto analítico dentro das próprias sociedades, com o objetivo de tornar mais humano o desenvolvimento das comunidades. Valorizar-se a si mesmos como sujeitos das próprias vidas e da história local e universal, pela capacidade de pensar sobre o todo e analisar tudo (RIZO, 2010, p. 68).

No entanto, na elaboração do relatório Delors, “a posição adotada pela comissão não se baseou em um modelo educativo que procurasse pontos comuns em todas as culturas para estabelecer princípios educativos" (RIZO, 2010, p. 69). Diante disso, a educação para a diversidade requer um Currículo Multicultural que apresente[...] propostas pedagógicas que respeitem e valorizem o pluralismo, materiais didáticos adequados (contendo informações, imagens, dados dos grupos minoritários), conteúdo e atividades didáticas capazes de responder às diferentes necessidades, interesses e capacidades dos alunos, flexibilidade na organização de programas, enfim, requer o 
desenvolvimento de processos educativos, metodologias e instrumentos pedagógicos que levem em conta as diferenças (CARVALHO, 2010, p. 44).

Diante das primeiras aproximações aqui debatidas, percebe-se, então, que a questão da diversidade é posta de forma específica, elaborando uma educação diferente para cada sujeito "excluído", buscando compreender os indivíduos de acordo com sua cultura, para que possa ser dada uma formação conforme as suas especificidades (LEAL, 2010). Como afirma Arroyo (apud LEAL, 2010, p. 11), "a própria política que se julga universalista e única, não o é, e nunca foi”. Pelo fato de se falar em diversidade, propondo uma educação para a diversidade, já se admite a exclusão de pessoas.

\section{CONCLUSÃO}

Ao encerrar esse texto ressalta-se que as discussões em torno das políticas para a Educação Inclusiva, diversidade cultural e formação de professores se intensificaram a partir da década de 1990, devido às mudanças ocorridas na política e na economia, com grande influência das agências internacionais. A educação "intercultural”, segundo os documentos da Unesco, é "o instrumento mais eficaz para promover a compreensão mútua entre as culturas e a solidariedade entre os povos".

Por meio da análise do Relatório foi possível apreender que o documento conduziu para que os currículos nas escolas se modifiquem a partir dos pressupostos do mercado, pois afirma que "para atender às diferentes necessidades dos sujeitos, o ensino deve ser personalizado e diversificado, e os currículos, flexíveis e dinâmicos" (DELORS, 2001, p. 58). Assim, o cidadão que se deseja formar é aquele a quem é atribuída maior responsabilidade, devendo agir por si próprio, em busca de uma sociedade mais justa e solidária.

No entanto, é preciso atentar para as armadilhas dessa educação para a diversidade cultural e social, pois tal discurso e pode obscurecer a compreensão da realidade, num sentido de que se almeja a manutenção da estrutura econômica e das desigualdades sociais. Contraditoriamente, essa educação não está voltada para a formação do ser humano como um todo, mas se apresenta como uma educação voltada para uma única especificidade, ou seja, o fato da diversidade cultural. Assim sendo, percebe-se que as ações educativas voltadas para a diversidade apresentam limites que não atendem o conceito da educação inclusiva, pois, admitem a existência da diversidade, mas se restringem em marcos culturais, perdendo de vista as relações entre os homens, as 
Políticas para a educação inclusiva, diversidade cultural e a formação de professores: primeiras aproximações

contradições e conflitos, os quais determinam as desigualdades e a exclusão social, não se adentrando nas questões maiores sobre a diversidade, as quais estão ligadas às mudanças no âmbito social, político e econômico (LEAL, 2010).

Diversas questões suscitam um amplo debate no campo da formação dos professores, especificamente com as atuais mudanças a serem instituídas com a Base Nacional Comum Curricular e distintas reformas em andamento no país. Ressalta-se que a intolerância, os diversos preconceitos e o racismo não é um problema relacionado apenas à cor ou à cultura de um povo, ou à falta de educação, mas se reporta, também, às questões culturais e econômicas.

\section{REFERÊNCIAS BIBLIOGRÁFICAS}

CANEN, Ana. Educação multicultural, identidade nacional e pluralidade cultural: tensões e implicações curriculares. Cadernos de pesquisa. São Paulo, n 11, p. 135-149, 2000.

CARVALHO, Elma Júlia Gonçalves. Educação e diversidade cultural. In:

CARVALHO, E. J. G.; FAUSTINO, R. C. (org.). Educação e diversidade cultural. Maringá: Eduem, 2010, p. 17-54.

DELLORS, Jacques. (Org.). Educação: um tesouro a descobrir. 3. Ed. São Paulo: Cortez, 2001. Relatório para a Unesco da Comissão Internacional Sobre a Educação Para o Século XXI.

FONSECA, Selva Guimarães. Globalização diminui as distâncias e lança o mundo na era das incertezas. Folha de São Paulo, São Paulo, 2 nov. 1997. Caderno Especial.

HOFLING, Eloísa de Matos. Estado e políticas (públicas) sociais. Cadernos Cedes. Ano XXI, n.55, Novembro, 2001.

LEAL, Leila. Educação e justiça social: sexto eixo da Conae pauta relação entre desigualdades sociais e processos educativos. Revista Poi saúde, educação, trabalho. Ano II, nº 9. Fundação Oswaldo Cruz. Rio de Janeiro, 2010.

MÉSZAROS, István. Para além do capital. São Paulo: Boitempo, Campinas: Ed. da Unicamp, 2002.

MOREIRA, Jani Alves da Silva; PINELLI, Jezika Bertoni; MATSUO, Talita. Políticas educacionais e diversidade: um debate para a atualidade. Anais do $5^{\circ}$ Seminário Nacional de Estado e Políticas Sociais. Cascavel: UNIOESTE, 9-12 outubro de 2011.

MOREIRA, Jani Alves da Silva. Políticas para educação infantil e a agenda E2030 no Brasil. Revista FAEEBA: Educação e Contemporaneidade. V. 28, n. 54, p. 77-96, jan.-abr. 2019 
OLIVEIRA, Dalila Andrade. Educação Básica: gestão do trabalho e da pobreza. Petrópolis: Vozes, 2000.

REILLY, C. A. Redistribuição de direitos e responsabilidades: cidadania e capital social. In: BRESSER PEREIRA, L. C; GRAU, N.C. O público não-estatal na reforma do Estado. Rio de Janeiro: Fundação Getúlio Vargas, 1999. P. 407-452.

RIZO, Gabriela. Relatório Delors: a educação para o século XXI.In: CARVALHO, E. J. G.; FAUSTINO, R. C. (org.). Educação e diversidade cultural. Maringá: Eduem, 2010, p. 55-83.

SANDRONI, Paulo. Novo dicionário de economia. 7 ed. São Paulo: Editora Best Seller, 1994.

TORRES, C. A. A escola precisa debater as influências da globalização. Revista Nova Escola. Ano XXIII, n. 212. p. 26-30. Maio, 2008.

UNESCO. Convenção sobre a proteção e promoção da diversidade das expressões culturais e artísticas. 2005.

\section{Credenciais das autoras}

MOREIRA, Jani Alves da Silva. Professora adjunto do Departamento de Teoria e Prática da Educação (DTP/UEM) e do Programa de Pós-Graduação em Educação (PPE/UEM), na linha de Política e Gestão em Educação. Mestrado e Doutorado em Educação pela Universidade Estadual de Maringá, com estágio de doutoramento sanduíche apoiado pela CAPES/PSDE, no Instituto de Educação da Universidade de Lisboa. Atualmente realiza pós-doutorado na Universidade Federal do Paraná (UFPR), com estágio pós-doutoral no Programa de Pós-Graduação em Educação da Faculdade de Educação da Universidade de Salamanca (USAL), na Espanha. É Líder do GEPEFI/CNPq - Grupo de Estudos e Pesquisa em Políticas Educacionais, Gestão e Financiamento da Educação. É associada à ANPED, ANPAE, FINEDUCA, ANFOPE e membro efetivo do Fórum de Educação Infantil do Paraná (FEIPAR/MIEIB), no GT Pirapó. E-mail: professorajani@homail.com

LIMA, Nicole de Oliveira. Graduanda de Letras Inglês pela Universidade Estadual de Maringá (UEM).

Endereço para correspondência: Jani Alves da Silva Moreira. Universidade Estadual de Maringá/ Departamento de Teoria e Prática da Educação (DTP/UEM), Av. Colombo, 5790 - Zona 7, Maringá - PR, 87020-900 E-mail: professorajani@ homail.com

Como citar este artigo (Formato ABNT): MOREIRA, Jani Alves da Silva; LIMA, Nicole de Oliveira. Políticas para a educação inclusiva, diversidade cultural e a formação de professores: primeiras aproximações. Educação, Psicologia e Interfaces, v. 3, Dossiê Inclusão e Diversidade, p. 122-134, 2019. DOI: https://doi.org/10.37444/issn-2594-5343.v3i4.232

Recebido: 08/10/2019.

Aceito: 20/10/2019. 